\title{
Xylohypha bantiana multiple brain abscesses in a patient with systemic lupus erythematosus
}

\author{
Khalid F AlHabib MBBS FRCPC ${ }^{1}$, Elizabeth A Bryce FRCPC ${ }^{2}$
}

KF AlHabib, EA Bryce. Xylohypha bantiana multiple brain abscesses in a patient with systemic lupus erythematosus. Can J Infect Dis 2003;14(2):119-120.

Xylohypha bantiana is a rare cause of cerebral fungal infection (phaeohyphomycosis). We report on a 72-year-old man who, while taking several immunosuppressive medications for systemic lupus erythematosus, presented with multiple bilateral cerebral abscesses caused by $X$ bantiana. The lesions were not surgically amenable and the patient died two months after discontinuing antifungal therapy.

Key Words: Brain abscess; Fungal infection; Immunosuppression; Xylohypha bantiana

\section{Abcès cérébraux multiples à Xylohypha ban- tiana chez un patient atteint de lupus érythé- mateux systémique}

Le Xylohypha bantiana est une cause rare d'infection fongique cérébrale (la phaéohyphomycose). Nous présentons le cas d'un homme de 75 ans qui, tandis qu'il prenait plusieurs immunosuppresseurs contre un lupus érythémateux systémique, a souffert de multiples abcès cérébraux bilatéraux causés par le X bantiana. Les lésions n'étaient pas atteignables par voie chirurgicale, et le patient est décédé deux mois après avoir cessé de prendre un traitement aux antifongiques.

\begin{abstract}
Cerebral phaeohyphomycosis caused by Xylohypha bantiana $\checkmark$ is a rare fatal disease that is becoming increasingly reported, particularly in immunosuppressed patients such as those undergoing transplant surgery $(1,2)$. Curative therapy depends on antifungal agents and the surgical drainage of the cerebral abscesses. We report on a patient taking immunosuppressive therapy for systemic lupus erythematosus who had multiple bilateral cerebral abscesses caused by $\chi$ bantiana.
\end{abstract}

\section{CASE PRESENTATION}

A 72-year-old man with a diagnosis of systemic lupus erythematosus was admitted to the hospital for adjustment of his immunosuppressive agents, which included high dose prednisone $(60 \mathrm{mg} /$ day $)$, hydroxychloroquine $(400 \mathrm{mg} /$ day $)$ and azathioprine $(150 \mathrm{mg} /$ day $)$. He was given a single dose of cyclophosphamide (1000 mg) before discharge. His medical history was remarkable for remote pulmonary tuberculosis that was treated successfully, steroid-induced diabetes, facial postherpetic neuralgia and paroxysmal atrial fibrillation. He was a nonsmoker and an avid gardener. Over the following two weeks, he experienced progressive confusion, difficulty with speech and reading, and urinary incontinence. He was nauseated and had intermittent night sweats. Twenty-four hours before readmission to his local hospital, his level of consciousness deteriorated.

A computed tomography (CT) scan of the brain, with and without contrast, revealed multiple bilateral cerebral ringenhancing lesions. The largest of these lesions was within the posterosuperior aspect of the right frontal lobe and measured $3 \mathrm{~cm}^{3}$. There was surrounding vasogenic edema and mild mass effect, but no evidence of herniation or sinus lesions. A CT scan of the chest was unremarkable. The patient began an empirical treatment of intravenous ceftriaxone, vancomycin and hydrocortisone $(80 \mathrm{mg})$ for a presumptive diagnosis of brain abscesses, and was transferred to our hospital.

On arrival, his temperature was $37.1^{\circ} \mathrm{C}$ and other vital signs were normal. He was drowsy but easily roused, and neck stiffness was noted. There was no facial weakness, the optic discs were normal and the pupils were reactive bilaterally. He had mild left arm pronator drift and increased tone, but normal deep tendon reflexes and plantar flexion bilaterally. Respiratory, cardiac and abdominal examinations were unremarkable.

Laboratory studies revealed an elevated white blood cell count of $18.2 \times 10^{9} / \mathrm{L}$, a hemoglobin level of $125 \mathrm{~g} / \mathrm{L}$ and a platelet count of $4.06 \times 10^{9} / \mathrm{L}$. Serum creatinine, electrolytes, glucose and liver function tests were normal. Four sets of blood cultures were negative for both bacterial and fungal growth. Abdominal ultrasound and paranasal sinus roentgenograms were normal.

The patient underwent an aspiration biopsy of one of the right cerebral hemisphere lesions, and samples of greenish brown thick fluid were sent for culture and histological examination. All three samples of brain aspirate fluid revealed numerous fungal elements on Gram stain. After six days, all fungal cultures (incubated at $28^{\circ} \mathrm{C}$ ) grew a velvety olive green mold on both brain-heart infusion and inhibitory mold agar

${ }^{1}$ University of British Columbia, Vancouver, British Columbia; ${ }^{2}$ Division of Medical Microbiology and Infection Control, Vancouver Hospital Eु Health Sciences Centre, Vancouver, British Columbia

Correspondence: Ms EA Bryce, Division of Medical Microbiology and Infection Control, JPN 1111, 899 West 12th Avenue, Vancouver Hospital EF Health Sciences Centre, Vancouver, British Columbia V5Z 1M9. Telephone 604-875-4759, fax 604-875-4359,

e-mail ebryce@vanhosp.bc.ca

Received for publication November 29, 2001. Accepted April 24, 2002 
(with gentamicin and chloramphenicol). A lactophenolaniline blue wet mount revealed brown septate hyphae with long chains of oval conidia. Distinct hila on the conidia were not present and conidial chain branching was infrequent. Growth occurred at $42^{\circ} \mathrm{C}$ and a diagnosis of $X$ bantiana was made that was later confirmed by the reference laboratory. Treatment with amphotericin B (1 mg/kg/day) was started immediately upon notification of the biopsy Gram stain results. The patient continued to deteriorate, and intravenous flucytosine $(0.3 \mathrm{~g}$ every $12 \mathrm{~h})$ and oral itraconazole ( $200 \mathrm{mg} /$ day) were added.

On day eight, the amphotericin was changed to the lipid complex formula ( $5 \mathrm{mg} / \mathrm{kg} /$ day) because of rising serum creatinine levels. The multiple cerebral lesions were not amenable to any neurosurgical drainage. The patient continued to have a fluctuating level of consciousness with no improvement in his neurological status. Twelve days after the initiation of amphotericin B and seven days after the addition of the other two antifungal medications, the family requested that all therapy be discontinued because of the lack of any clinical response and the absence of a curative intervention. The patient remained unresponsive until he died two months later. An autopsy was not performed.

\section{DISCUSSION}

X bantiana (previously known as Cladophialophora bantianum and Cladosporium trichoides) has been increasingly recognized as a cause of human disease $(1,3)$. It is a dematiaceous fungus that produces melanin or melanin-like pigments. The fungus is ubiquitous and is found on wood and plant matter. Factors that suppress cell-mediated immunity, such as chronic steroid therapy, organ transplantation and cancer, increase the risk for acquisition of this fungus, although it has also been reported in immunocompetent patients $(2,4,5)$. In addition to the use of immunosuppressive agents, the patient also had steroidinduced diabetes, which is known to impair neutrophil, macrophage and complement function (6). It is assumed that the fungus is inhaled and the paranasal sinuses act as a primary portal of entry to the central nervous system $(5,7)$. Our patient's gardening history certainly supports inhalation as the route of acquisition in his case.

It is interesting to note that the cultures grew rapidly (within six days) on brain-heart infusion agar, while it has been previously reported that this media is unsuitable for growth and that growth of $X$ bantiana is slow (8). Inhibitory mold agar also successfully grew the fungus.

The only proven curative therapy for cerebral phaeohypomycosis caused by $X$ bantiana is neurosurgical excision of the abscesses, regardless of the antifungal medications used. The mortality for this disease is very high, exceeding more than $50 \%$ even with aggressive medical and surgical treatment (9). Sood et al (1) reported a clinical improvement after surgical excision of a brain abscess and six weeks of treatment with fluconazole. A patient who had undergone cardiac transplant surgery died after surgical treatment combined with sequential amphotericin B and itraconazole (2). The optimal antifungal regimen and duration of therapy are unknown. It was decided to treat our patient with a combination of agents (amphotericin B, flucytocine and itraconazole) that had resulted in the regression of cerebral lesions in a renal transplant patient with a similar clinical picture (10). It may be that the newer antifungal agents, such as the enhanced spectrum azoles or the echinocandins, may be of benefit in future therapy of this unusual infection. However, no clinical reports on the use of these agents against $X$ bantiana are available in the literature.

The patient's rapid neurological deterioration illustrates the potential virulence of $X$ bantiana and the need to proceed to definitive diagnosis early in the course of the disease. Treating physicians should be cognizant of this fungal pathogen when presented with a history of immunosuppression and multiple cerebral lesions. Early and aggressive antifungal therapy with neurosurgical drainage, where feasible, is crucial in achieving a successful outcome.

\section{REFERENCES}

1. Sood P, Dogra V, Thakur A, et al. Brain abscess due to Xylohypha bantiana. Scand J Infect Dis 2000;32:708-9.

2. Osiyemi OO, Dowdy LM, Mallon SM, et al. Cerebral phaeohyphomycosis due to a novel species: report of a case and review of the literature. Transplantation 2001;71:1343-6.

3. Kwon-chung KJ, Wickes BL, Plaskowitz J. Taxonomic clarification of Cladosporium trichoides Emmons and its subsequent synonyms. J Med Vet Mycol 1989;27:413-26.

4. Rossmann SN, Cernoch PL, Davis JR. Dematiaceous fungi are an increasing cause of human disease. CID 1996;22:73-80.

5. Middleton FG, Jurgenson PF, Utz JP, et al. Brain abscess caused by Cladosporium trichoides. Arch Intern Med 1976;136:444-8.

6. McMahon MM, Bistrian BR. Host defences and susceptibility to infection in patients with diabetes mellitus. Infect Dis Clin North Am 1995;9:1-9.

7. Brown JW III, Nadell J, Sanders CV, et al. Brain abscess caused by Cladosporium trichoides (Bantianum): a case with paranasal sinus involvement. South Med 1976;69:1519-23.

8. Kwon-Chung KJ, Bennett E, eds. Medical Mycology. Philadelphia: Lea \& Febiger, 1992:639-45.

9. Dixon DM, Walsh TJ, Merz WJ, et al. Infections due to Xylohypha bantiana (Cladosporium trichoides). Rev Infect Dis 1989;11:515-25.

10. Salama AD, Rogers T, Lord GM, et al. Multiple Cladosporium brain abscesses in a renal transplant patient: aggressive management improves outcome. Transplantation 1997;63:160-2. 


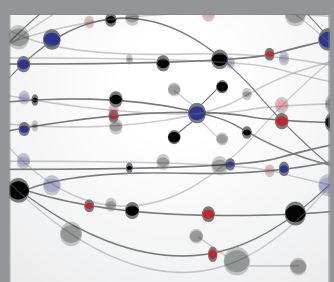

The Scientific World Journal
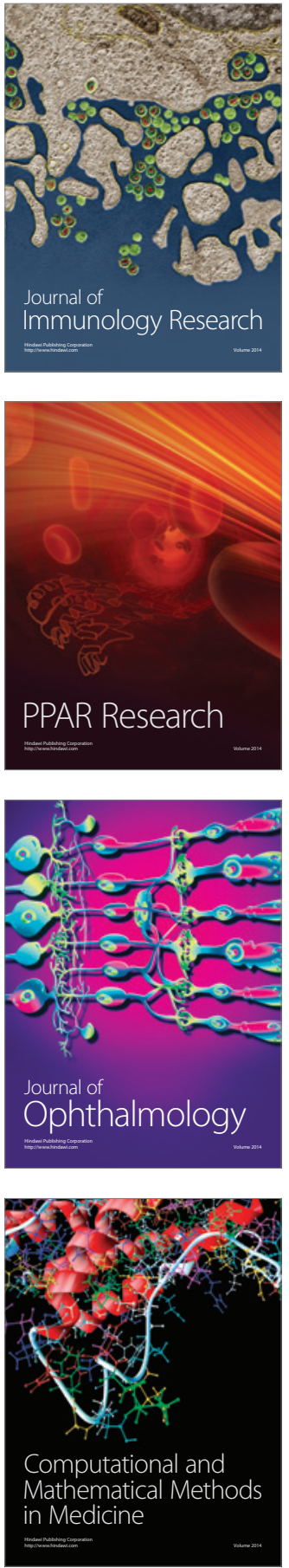

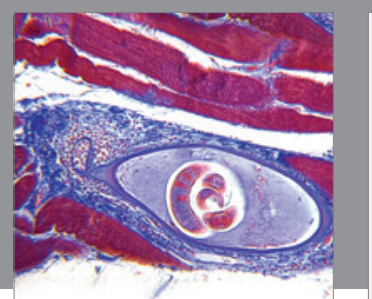

Gastroenterology Research and Practice

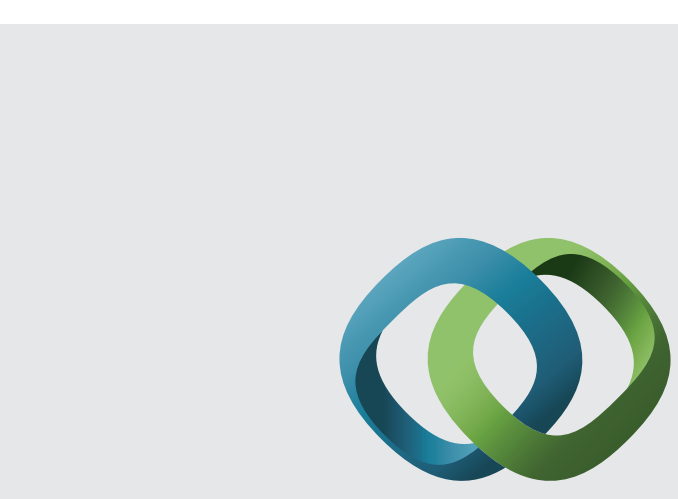

\section{Hindawi}

Submit your manuscripts at

http://www.hindawi.com
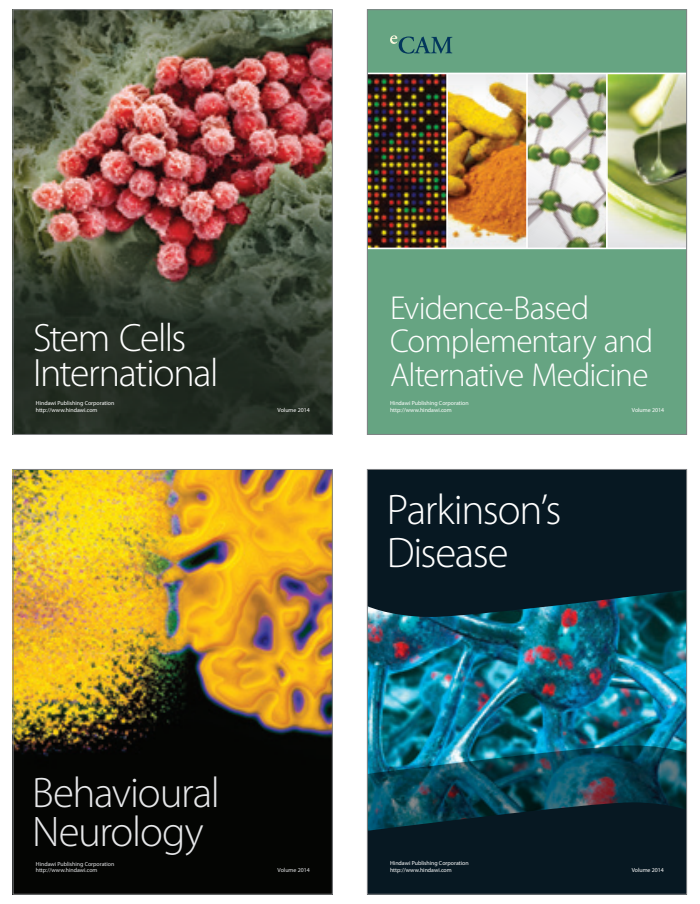
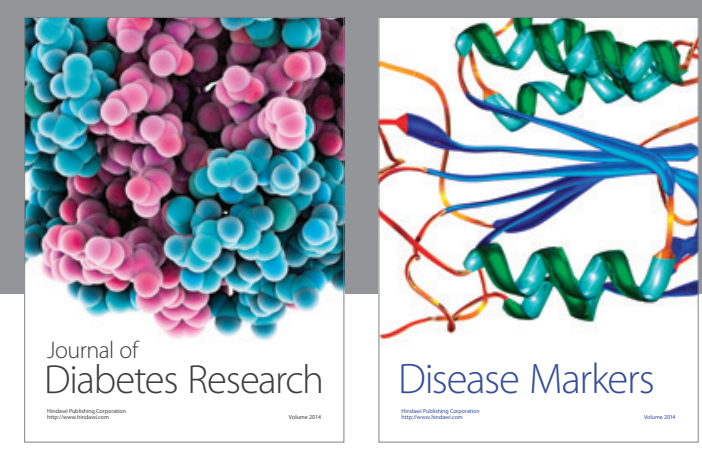

Disease Markers
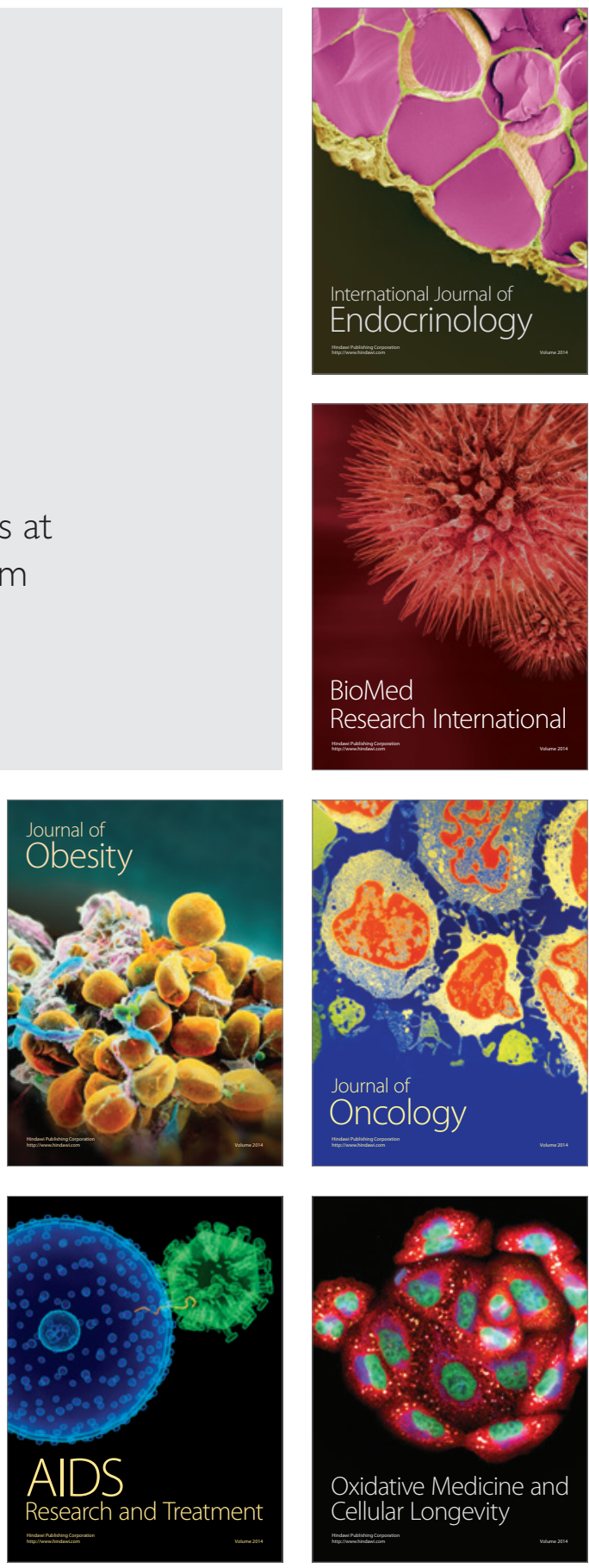